\title{
A Simple Dosing System for Continuous Stream Dosing1,2
}

\author{
Paul J. Eisele ${ }^{3}$ \\ Department of Environmental Health \\ University of Michigan \\ Ann Arbor, Michigan 48104
}

\begin{abstract}
A simple mechanical dosing apparatus to continuously dose streams with chemical solutions involves a modified Sutro weir and a simple lever-float system. This dosing device is easily constructed, inexpensive, and quite reliable under conditions of minor flow variation (a seasonal fluctuation of one order of magnitude or less). It maintained an average stream concentration variation of only \pm 10 percent during a year of low level pesticide dosing.
\end{abstract}

To evaluate toxicant effects on stream organisms during long periods of exposure, or to control pest organisms in streams, it is desirable to maintain a constant stream concentration of toxicant regardless of discharge. Most current dosing devices deliver constant dosage rates into the stream regardless of changes in stream flow. Electrical dosing systems using syringe pumps with feedback systems are expensive and require power sources. The system described herein is mechanically operated by stream level and thus requires no external power source.

This system was used to evaluate the effects of continuous low level methoxychlor exposure on both riffle and pool dwelling stream invertebrate communities (Eisele 1974).

\section{MATERIALS AND METHODS}

A small tributary of the Saline River, Michigan, was chronically dosed by a mechanical dosing device. Figure 1 shows its major constituent the modified Sutro weir. This type of weir relates flow to head linearly by the nature of its nonlinear opening. The required dimensions of the nonlinear opening of the weir can be generated through the use of the equation described by Smith (1943):

\footnotetext{
${ }^{1}$ Portions adapted from a thesis submitted in partial fulfillment of requirements for the degree of Doctor of Philosophy.

${ }^{2}$ This work was completed under Environmental Protection Agency Research Fellowship U910010.

${ }^{3}$ Present address: Ecologist, Environmental Division, Stone \& Webster Engineering Corporation, P.O. Box 2325, Boston, Massachusetts 02107.
}

$$
\mathrm{Q}=1.57 \mathrm{C}(2 \mathrm{~g})^{1 / 2} \mathrm{~W} \mathrm{H}^{3 / 2}
$$

where $Q$ is stream flow in cubic meters per second, $\mathrm{C}$ is a constant weir coefficient, usually between 0.60 and $0.63, \mathrm{~g}$ is gravity, $\mathbb{W}$ is width of the weir opening in meters, and $\mathrm{H}$ (in meters) is head behind the weir. $\mathrm{C}$ and $\mathrm{g}$ are constants, and thus the width of the weir for various flows can be calculated by varying $Q$ and $H$ using the following equations:

$$
\begin{gathered}
\mathrm{W} \mathrm{H}^{1 / 2}=\frac{\mathrm{Q}}{1.57 \mathrm{C}(2 \mathrm{~g})^{1 / 2} \mathrm{H}}=\mathrm{K} \\
\mathrm{W}=\frac{\mathrm{K}}{\mathrm{H}^{1 / 2}}
\end{gathered}
$$

where $\mathrm{K}$ indicates the constant relationship of $\mathrm{W}$ and $\mathrm{H}$. Therefore, setting a certain $\mathrm{H}$ for a known $Q$, one can generate $W$ through a series of iterative increases in both $\mathrm{Q}$ and $\mathrm{H}$.

The weir for this study was designed to handle flows varying from 0.0142 to 0.425 $\mathrm{m}^{3} / \mathrm{sec}$ with only a small increase in head. The dimensions of the weir opening were $2.44 \mathrm{~m}$ width (W) at its base and $0.5 \mathrm{~m}$ in height $(\mathrm{H})$. The weir was constructed of marine plywood edged with aluminum stripping. It was buried in the stream bed so that the head behind the weir was related to stream flow at the time of installation.

Since flow is linearly related to head using this type of weir, dosing can be related to stream flow by means of a simple lever system. A stilling basin (Fig. 2) with a float attached to one end of the pesticide 


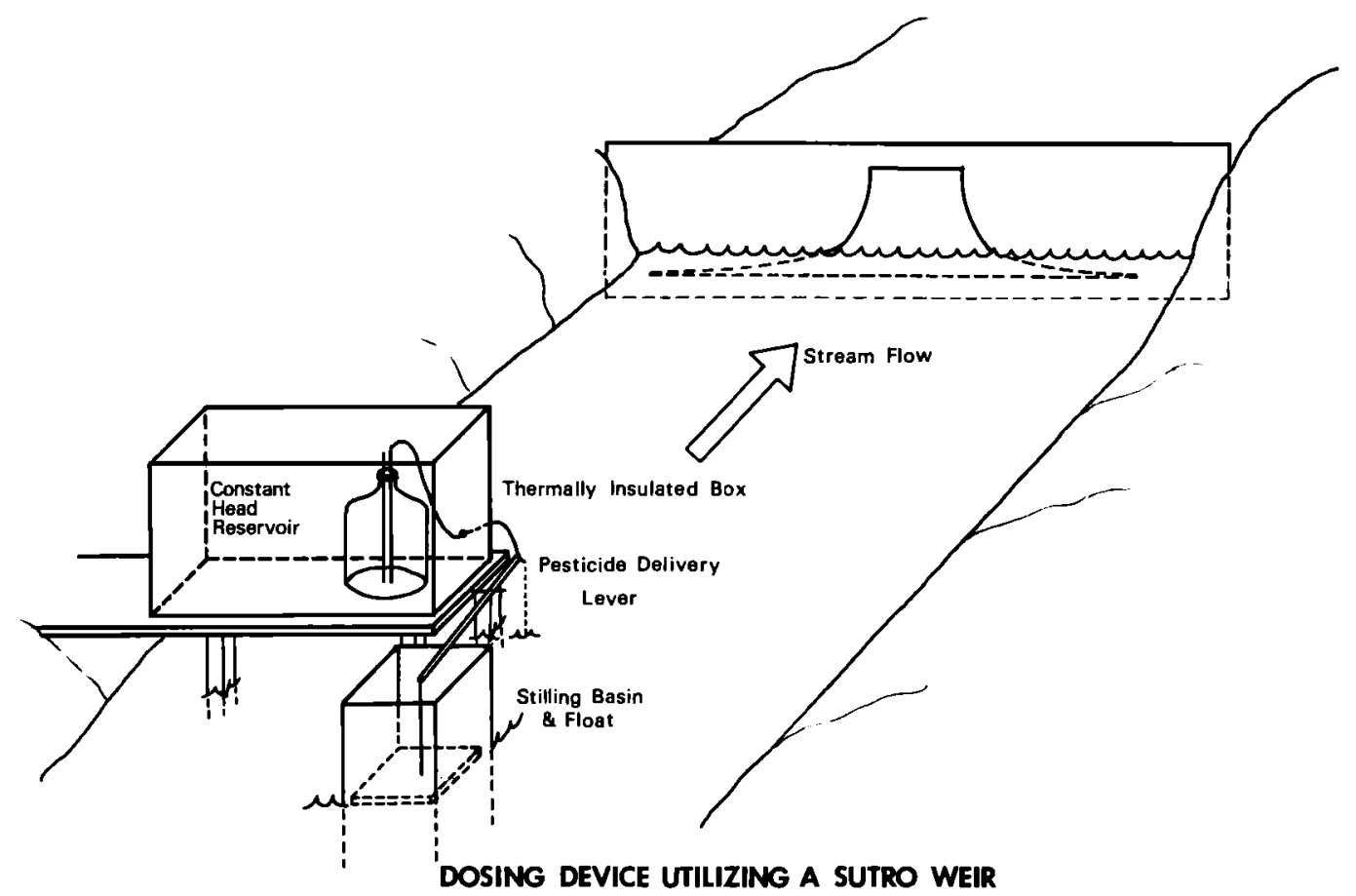

FIGURE 1. - Schematic drawing of the stream dosing device showing the Sutro weir and major components of the doser.

delivery lever regulates the rate of delivery of the toxicant. As the flow increases, the head behind the weir increases, thus raising the float and lowering the pesticide delivery tubing and increasing the rate of pesticide delivery. The toxicant can be stored in any vessel modified to be a constant head reservoir (modified Mariotte bottle).

Thick-walled teflon pressure tubing is used for pesticide delivery. The length of the delivery tubing is calculated from a theoretical equation governing laminar flow, which relates delivery tube geometry, fluid properties of the dosing solution, and flow to head loss:

$$
\mathrm{L}=\frac{\mathrm{d}^{4} \rho \mathrm{g} \Delta \mathrm{h}}{128 \mu \mathrm{q}}
$$

where $d$ is the interior diameter of the delivery tubing, $\rho$ is the density of the dosing solution, $\mathrm{g}$ is gravity, $\mu$ is the viscosity of the dosing solution, $q$ is the predetermined flow rate of the pesticide solution, and $\Delta \mathrm{h}$ is the predetermined head loss controlled by the lever. The pesticide delivery lever (Fig. 2) converts $\Delta H$ (height of the head behind the weir) to $\Delta h$ (which governs the pesticide delivery rate).

The dosing rate, $q$, may be monitored by comparing the drip rate into a graduated cylinder to different stages of stream flow, Q.

In the present system, the constant head reservoir was located in a heavily insulated box, as an acetone-water solution of methoxychlor was used in dosing. The viscosity and density of acetone changes with temperature change, which can result in differential flow rates.

\section{RESULTS AND DISCUSSION}

The present dosing system was operated for over one year (July 18, 1972 to July 29, 1973). Stream dosing was occasionally interrupted by flooding and freezing temperatures. Temperature fluctuations also caused temporary dosing stoppages due to 


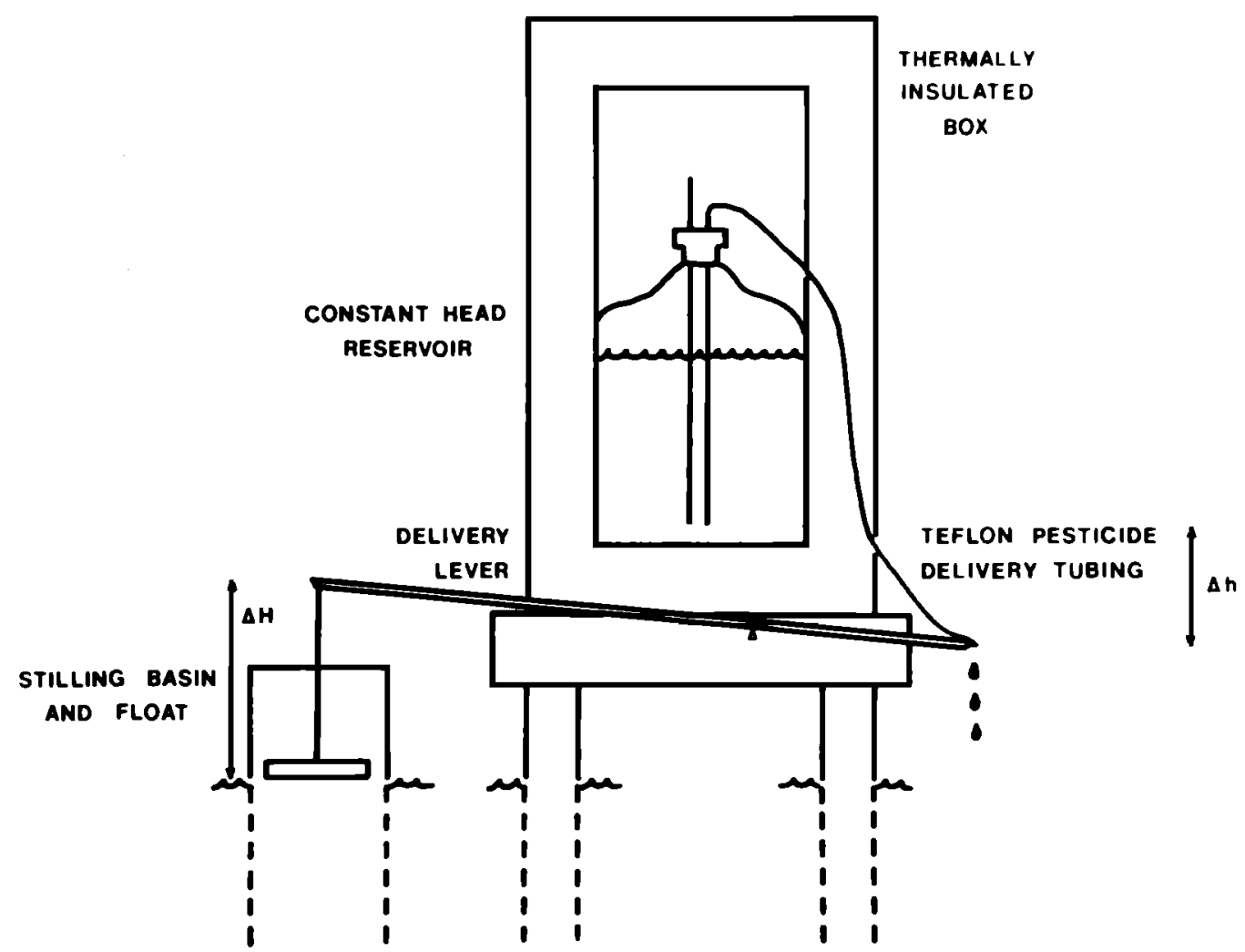

FIGURE 2. - Schematic drawing of the dosing apparatus showing, diagrammatically, the relationship between $\Delta \mathrm{H}$ and $\Delta \mathrm{h}$.

changes in air pressure in the constant head reservoir. Averaged over the year, however, the dosing was consistent for five days of every week.

The calculated dosing rate was set to maintain a $0.2 \mu \mathrm{g} /$ liter stream concentration. Water samples were collected at mid-depth and mid-channel in the stream to monitor pesticide concentrations during the year of dosing. The mean pesticide concentration $39 \mathrm{~m}$ downstream from the dosing apparatus (with 95 percent confidence limits) was $0.17 \pm 0.04 \mu \mathrm{g} /$ liter $(n=30)$ while $102 \mathrm{~m}$ downstream the mean concentration was $0.23 \pm 0.02 \mu \mathrm{g} /$ liter $(n=30)$. The observed difference in measured methoxychlor concentrations at these two locations was due primarily to the close proximity of the first area to the dosing apparatus. At low stream flow, mixing was complete in this area, but at high stream flows this probably was not the case. Lowest pesticide concentrations usually occurred during periods of high stream turbidity. Presumably the methoxychlor was absorbing to settleable solids and being removed from the water column.

This type of dosing system was effective in maintaining a continuous pesticide concentration in a small stream. The weir was effective in obtaining a linear flow in this field situation, except during flooding. The use of this type of weir represents an extension of the use of Sutro weirs which have primarily been used under conditions of controlled flow (e.g., sewage treatment plants). Much of the dosing variation would be reduced if the viscosity of the dosing mixture were less subject to temperature change than the acetone-water mixture. The dosing system, as a whole, is well adapted for use in primitive areas. 


\section{LITERATURE CITED}

EISELE, P. J. 1974. The effects of methoxychlor on aquatic invertebrate populations and com- munities. Ph.D. Thesis. The University of Michigan, Ann Arbor, Michigan. 151 pp.

SMITH, E. G. 1943. A weir with flow proportional to head. Eng. News-Record (July 8), pp. 72-73. 